\title{
You Have Become a Graphic NOVEL IN MY DREAMS
}

\section{WES LEE}

Storyboarded

in dazzling scenes

so I can't go back,

only to the dazzling scenes.

The night after

when you appeared

wearing a billowing nightie;

standing there like a movie ghost

not speaking,

and it was all in the eyes.

I kept yelling You are dead!

You didn't know.

A week later

you appeared on the back of my motorbike,

adjusted the pressure on the handlebars

to steer

me away from a head-on collision. 
Lying for hours on the sofa in the small apartment surrounded by your plants,

hardly moving as if I was some other animal, a slow insect

staring ahead

very quiet

very very quiet,

at first I wanted you to come back

but I knew you would be changed,

like a zombie

or a form that looked like you but had a new

malevolence.

I can't cut you out of the frame

A close-up of an eye

A bead of sweat

A quick spurt of blood

Drool, saliva

A spine slithering away

A wide-brimmed hat with an upturned eye

A manic grin

A hand on a doorknob

A light bulb coming on

The slant of rain on a roof

with the descriptor HISS! 